\title{
Granuloma inguinale of cervical lymph nodes simulating tuberculous lymphadenitis: two case reports and review of published reports
}

\author{
A L FREINKEL
}

From the Department of Anatomical Pathology, School of Pathology of the South African Institute for Medical Research and University of the Witwatersrand, Johannesburg, South Africa

SUMMARY Granuloma inguinale (donovanosis) is commonly thought to be a superficial disease, which spreads by continuity and does not affect the regional lymph nodes. Two patients with the disease affecting lymph nodes in the neck are reported from a series of 108 seen in a continuing study of granuloma inguinale. An immunofluorescent antibody test is described that showed antigenic relatedness between the intracellular organisms in these patients and in patients with typical genital granuloma inguinale. Lymphadenitis associated with granuloma inguinale appears to be a stage in the pathogenesis of the pseudobubo, an uncommon feature of this disease.

The common concept of the natural history of granuloma inguinale is that the disease does not affect the regional lymph nodes. Granuloma inguinale is an indolent, but slowly progressive, superficial disease of the skin and mucosa of the genitalia of both sexes. It appears to be sexually transmitted, but this is controversial. Diagnosis of the disease depends on showing Donovan bodies either in smears of deep scrapings from the base of the lesions or in histological sections ${ }^{12}$ of biopsies of the lesions. The smears may be stained with Wright's or Papanicolaou stains. ${ }^{3-5}$ The WarthinStarry silver impregnation method is used on histological preparations.

The disease often extends from the genitalia to the perineum and the inguinal areas. Satellite lesions are commonly present. Elephantiasis, said to be due to blockage of the lymphatics, may be present. Six percent of patients have associated extragenital disease, ${ }^{67}$ usually of the mouth and neck, which is thought to be due to autoinoculation. ${ }^{8}$ Rarely, there is associated remote bone disease that is explicable only on the basis of haematogenous spread. Even though there may be elephantiasis and secondary infection, the regional lymph nodes are normally not obviously enlarged and are therefore not biopsied.

Published reports have paid little attention to the condition of the lymph nodes in granuloma inguinale.

Address for reprints: Dr A L Freinkel, Department of Anatomical Pathology, School of Pathology, The South African Institute for Medical Research, PO Box 11074, East Rand 1462, Republic of South Africa.

Accepted for publication 29 April 1988
This paper describes two cases of granuloma inguinale affecting lymph nodes, both located in the unusual location of the neck. These two cases form part of a continuing study of granuloma inguinale, which in southern Africa appears to be endemic in the eastern Transvaal, ${ }^{49}$ Swaziland (Frankel AL, unpublished observation), and Natal (Cooper K et al, unpublished observation).

\section{Patients, materials, and methods}

The techniques used for the histological examination of the two patients were those used routinely for histological confirmation of genital ulceration at the Boksburg-Benoni branch laboratory of this institute. ${ }^{1011}$ Most of 108 patients with granuloma inguinale who have been assessed to date in a continuing review were confirmed histologically at this laboratory, ${ }^{4111}$ which provides a histological service to hospitals in the eastern Witwatersrand and southern and eastern Transvaal.

In addition to standard histological techniques, a fluorescent antibody test was used to show antigenic relatedness between the intracellular organisms found in the two patients described here and in patients with typical granuloma inguinale with genital ulceration. Using Donovan bodies in tissue sections as an antigen in an indirect fluorescent antibody test, our laboratory has shown a high degree of specificity and sensitivity at serum titres of $1 / 160$ or more. This immunofluorescent technique was evaluated in 39 patients and 206 control sera from persons suffering from sexually transmitted 
diseases other than donovanosis and blood donors from within and outside a region endemic for granuloma inguinale. To show strong antigenic cross reactivity between the bacilli seen in the lymph node sections and typical Donovan bodies from granuloma inguinale cases, the sera of eight patients with genital donovanosis were used as a source of putative antibodies specific to donovanosis. Sections of the cervical lesions were dewaxed and rehydrated in graded alcohols. The sections were then incubated in a humidity chamber with serum (diluted $1 / 160$ ) from each of the eight patients with histologically confirmed genital lesions of granuloma inguinale as well as with serum from one normal control. The sections were washed, incubated in the humidity chamber with a $1 / 20$ dilution of rabbit anti-human globulin conjugated with fluorescein isothiocyanate, stained with Evans blue, and mounted in a non-fluorescent mounting medium.

Examining the sections under ultraviolet light characteristically shows diffuse fluorescence of the cytoplasm of the plasma cells present in the inflammatory infiltrate and a striking fluorescence of the intracellular Donovan bodies. The plasma cell fluorescence is non-specific because of the use of human serum as the source of antibodies. It is the fluorescence of the Donovan bodies, which appear as clusters of brightly fluorescent oval rings within scattered large mononuclear cells, that indicates antigenic relatedness.

\section{Results}

Two of the 108 patients studied to date had enlarged lymph nodes in the neck, which were biopsied to confirm the clinical diagnosis of tuberculosis. Both were treated at hospitals in the eastern Transvaal.

\section{CASE 1}

A boy aged 11 presented with a mass in the left side of the neck, which was biopsied. The histological diagnosis was extragenital granuloma inguinale of the neck. Little further clinical information was available, except that the patient responded to antituberculous treatment.

Microscopically, the biopsy specimen showed adipose tissue and portions of lymph node almost completely replaced by granulation tissue in which there were numerous small, thin walled vessels and an inflammatory infiltrate of neutrophils, histiocytes, and occasional plasma cells, but no lymphocytes. Many of the histiocytes were vacuolated and many of these vacuoles contained short rod shaped organisms. Warthin-Starry silver impregnation staining showed intracellular Donovan bodies. The perinodal adipose tissue showed some inflammation, but contained no

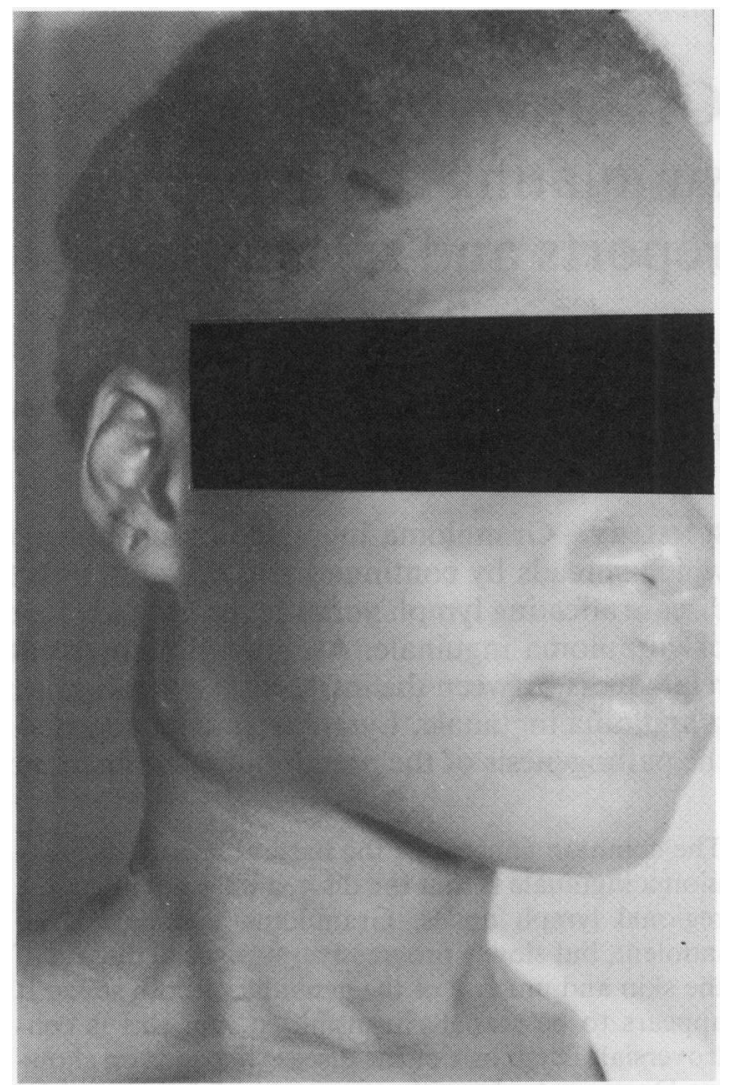

Fig 1 Girl aged 16 with painful enlargement of lymph nodes in the neck for two months.

Donovan bodies. Sections prepared with the immunofluorescent antibody technique showed intracellular clusters of brightly fluorescent oval bodies corresponding with Donovan bodies, which were not present in the control section treated with normal human serum.

\section{CASE 2}

A nulliparous girl aged 16 presented with enlarged painful lymph nodes on both sides of the neck (fig 1) and both inguinal areas, which had been noted for two months. The skin of the right inguinal area was ulcerated. The patient was anaemic and had severe oedema of the legs. Eight months previously she had had iron treatment for severe anaemia (haemoglobin concentration $41 \mathrm{~g} / 1$ ) associated with bilharzia. At that time ova of Schistosoma haematobium had been recovered from the urine and $S$ mansoni from the stools. Physical examination showed no other abnormality apart from a vaginal discharge. The patient had a normal temperature, a pulse rate of 120 beats/ minute, and blood pressure of $80 / 50 \mathrm{~mm} \mathrm{Hg}$. Her chest 


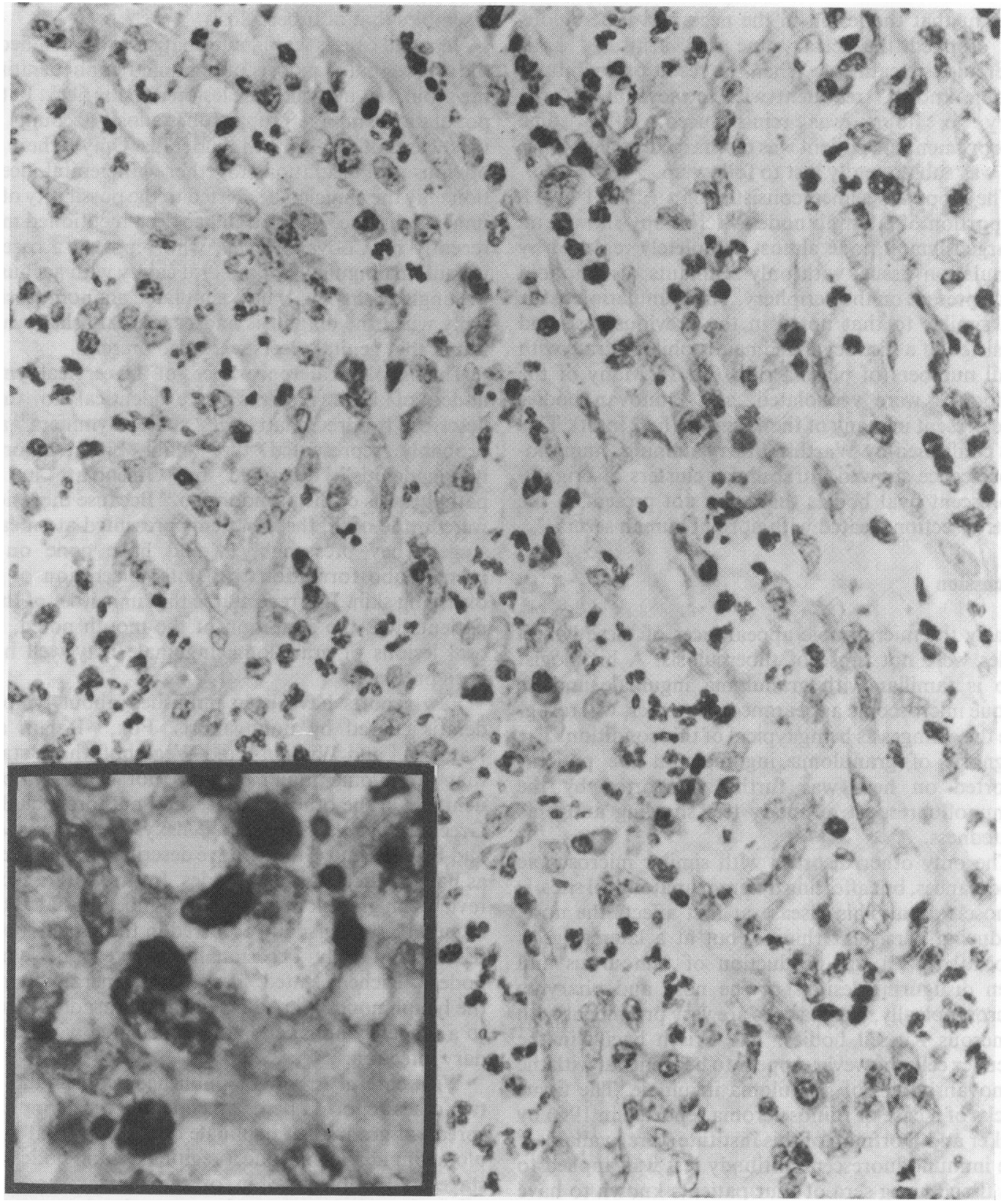

Fig 2 Granulation tissue replacing lymph node infiltrated with pale staining histiocytes, neutrophils, and small numbers of plasma cells. Note vacuoles in many histiocytes. Inset: Donovan bodies in vacuoles of histiocytes. (Haematoxylin and eosin)

$x$ ray was normal. Haematological examination showed a haemoglobin concentration of $72 \mathrm{~g} / \mathrm{l}$, a leucocyte count of $9.7 \times 10^{9} / 1$, a mean corpuscular haemoglobin of $26 \mathrm{pg}$, and a mean corpuscular haemoglobin concentration of $290 \mathrm{~g} / \mathrm{l}$. The erythrocyte sedimentation rate was $30 \mathrm{~mm}$ in the first hour

\section{(Westergren).}

After three days the patient was transfused with two units of blood, and treatment with tetracycline was started because the inguinal lesion was suspected of being granuloma inguinale. When the cervical lymph node was biopsied the following day, the clinicians 
thought that the lesion in the neck was tuberculous and stopped the tetracycline and instituted antituberculous treatment. When the result of the biopsy became known, treatment with tetracycline $500 \mathrm{mg}$ every six hours was reintroduced. After some improvement the patient was discharged 18 days later. She was subsequently lost to follow up.

The biopsy specimen consisted of a $1.5 \times 1 \times 0.8$ $\mathrm{cm}$ portion of a lymph node. Microscopy showed an enlarged lymph node almost completely replaced by granulation tissue, with only remnants of lymphoid tissue present on the periphery. The granulation tissue was similar to that noted in the previous case and consisted of a histiocyte and neutrophil infiltrate with small numbers of plasma cells (fig 2). Many of the histiocytes were vacuolated, and Donovan bodies were present in many of the vacuoles (fig 2 inset). This was confirmed by Warthin-Starry staining. Immunofluorescence showed intracellular clusters of brightly fluorescent oval bodies that were not present in the control section treated with normal human serum.

\section{Discussion}

Clearly the microscopic appearances of these lymph nodes were not those of tuberculosis. A histologist who is familiar with granuloma inguinale and its unique microscopic appearances, however, will recognise the changes as being typical of this condition. The diagnosis of granuloma inguinale in the patients reported on here was further supported by the immunofluorescent antibody test showing antigenic relatedness.

The only other disorder with similar microscopic appearances, but affecting different anatomical sites, is rhinoscleroma. This disease at first affects the nose, producing persistent rhinitis, but at a later stage is associated with the production of tumourous and often disfiguring lesions of the nose and pharynx. Microscopically, plasma cells are very prominent with numerous Russell bodies. The Frisch bacilli in the Miculicz cells, however, appear to be identical with the Donovan bodies of granuloma inguinale. The tissue blocks of a case of rhinoscleroma reported in 1956 by Becker and Dorfman of this institute were available. ${ }^{12}$ The immunofluorescent antibody test was applied to this tissue using sera of four patients known to have granuloma inguinale. These tests showed only faint fluorescence with low dilutions of the serum, and from experience with many other cases of granuloma inguinale this was interpreted as not showing relevant antigenic relatedness. Histoplasmosis may also be considered. The organisms are somewhat larger than Donovan bodies, are oval or round in shape, and are present throughout the cytoplasm of the cell, not in vacuoles. The architecture of the lesion, furthermore, resembles that of tuberculosis.

Venereal causes would automatically be included in the differential diagnosis of inguinal lymphadenitis in the groin, but not when the lesion is in the neck. In this population and age group, tuberculosis accounts for most cases of cervical lymphadenitis. Only if there are obvious oral ulcerations together with genital ulceration may the clinician be alerted to the possibility of an unusual disease. This pitfall has been mentioned most recently by Coovadia $e t$ al, who reported a case of granuloma inguinale of the oral cavity with a sinus to the angle of the jaw, which simulated actinomycosis. ${ }^{13}$ Only when the diagnosis had been established was it found that genital ulcers were also present.

The histological appearances of the cervical lymph nodes of both patients were identical to those described by Greenblatt $e$ e $a l^{14}$ and by Symmers, ${ }^{15}$ and probably represented the "mild but temporary lymphadenitis" described by Greenblatt in the pathogenesis of the pseudobubo. ${ }^{14}$ Because the lesions were in the neck, these patients presented at an early stage. They presumably would have gone on to pseudobubo formation with later ulceration of the overlying skin. It is regrettable that in neither of these patients was the condition of the mouth noted, but oral lesions of granuloma inguinale may well have been present.

Few reports have been published about lymphadenitis caused by donovanosis. Fox, ${ }^{16}$ Rajam and Rangiah,' and Wistrand and Wegerhoff' have stated that granuloma inguinale does not cause lymphadenitis. On the other hand, several authors including Greenblatt et al, ${ }^{14}$ Sobel and Pensky, ${ }^{17}$ Jennison et al,${ }^{18}$ and Brigden and Guard ${ }^{19}$ have described their patients as having affected lymph nodes. In three more recent reviews on granuloma inguinale, Kuberski stated that inguinal lesions usually occurred in the subcutaneous tissues and only occasionally affected the lymph nodes, ${ }^{20}$ Richens stated "it does not generally involve the lymph nodes", 21 and Sehgal and Prasad only refer to a tender lymphadenopathy associated with secondary infection. ${ }^{22}$

With careful review of published reports and the two cases reported here, we conclude that lymphatic spread of granuloma inguinale does occur, that granuloma inguinale may affect regional lymph nodes as a stage in the progression of the disease, and that affected neck lymph nodes may simulate cervical tuberculous lymphadenitis clinically, particularly in the absence of obvious ulceration of the lips or mouth.

\section{References}

1 Goldzeiher M, Peck SM. Granuloma venereum (inguinale). Studies on etiology and pathology. Arch Pathol Lab Med 1926;1:511-23.

2 Pund ER, Greenblatt RB. Specific histology of granuloma inguinale. Arch Pathol Lab Med 1937;23:224-9. 
3 de Boer AL, de Boer F, van der Merwe JV. Cytologic identification of Donovan bodies in granuloma inguinale. Acta Cytol (Baltimore) 1984;28:126-8.

4 Freinkel AL. Granuloma inguinale (donovanosis). South African Journal of Sexually Transmitted Diseases 1984;4:43-7.

5 Leiman G, Markowitz S, Margolius KA. Cytologic detection of cervical granuloma inguinale. Diagnostic Cytopathology 1986;2:138-43.

6 Greenblatt RB, Torpin R, Pund ER. Extragenital granuloma inguinale. Archives of Dermatology and Syphilology 1938;38:358-62.

7 Rajam RV, Rangiah PN. Donovanosis (granuloma inguinale, granuloma venereum). Geneva: World Health Organisation. (WHO Monograph Series No 24.) 1954: 25-6.

8 Rajam RV, Rangiah PN, Anguli VC. Systemic donovanosis. British Journal of Venereal Diseases 1954;30:73-80.

9 Wistrand R, Wegerhoff F. Granuloma inguinale in the Eastern Transvaal. S Afr Med J 1985;67:13-5.

10 Freinkel AL, Counihan RJ. Granuloma inguinale (donovanosis) in South Africa. S Afr Med J 1983;63:599-601.

11 Freinkel AL. Histological aspects of sexually transmitted genital lesions. Histopathology 1987;11:819-31.

12 Becker BJP, Dorfman RF. Rhinoscleroma (scleroma): report of a case in South Africa. S Afr Med J 1956;30:581-4.

13 Coovadia YM, Steinberg JL, Kharsany A. Granuloma inguinale (donovanosis) of the oral cavity. S Afr Med J 1985;68:815-7.

14 Greenblatt RB, Dienst RB, Pund ER, Torpin R. Experimental and clinical granuloma inguinale. JAMA 1939;113:1109-16.

15 Symmers WStC. The lymphoreticular system. In: Systemic pathology. 2nd ed. Edinburgh: Churchill Livingstone, 1978;vol 2:593.

16 Fox H. Granuloma inguinale: its occurrence in the United States. JAMA 1926;87:1785-90.

17 Sobel N, Pensky N. Bubonulus in granuloma inguinale. Archives of Dermatology and Syphilology 1943;48:494-6.

18 Jennison DB, Helwig EB, Milstone JH. Granuloma inguinale involving buttock and lymph node. Archives of Dermatology and Syphilology 1947;55:342-54.

19 Brigden M, Guard R. Extragenital granuloma inguinale in North Queensland. Med J Aust 1980;2:565-7.

20 Kuberski T. Granuloma inguinale (donovanosis). Sex Transm Dis 1980;7:29-36.

21 Richens J. Donovanosis-a review. Papua New Guinea Med J 1985;28:67-74.

22 Sehgal VN, Prasad ALS. Donovanosis. Current concepts. Int J Dermatol 1986;25:8-16. 